\title{
Endocrine Responses to Overreaching Before and After 1 Year of Weightlifting
}

\author{
Andrew C. Fry, William J. Kraemer, Michael H. Stone, \\ Beverly J. Warren, Steven J. Fleck, Jay T. Kearney, \\ and Scott E. Gordon
}

Catalogue Data

Fry, A.C., Kraemer, W.J., Stone, M.J., Warren, B.J., Fleck, S.J., Kearney, J.T., and Gordon, S.E. (1994). Endocrine responses to overreaching before and after 1 year of weightlifting. Can. J. Appl. Physiol. 19(4): 400-410. (C) 1994 Canadian Society for Exercise Physiology.

Key words: testosterone, cortisol, weightlifting, overtraining

Mots-clés: testostérone, cortisol, haltérophilie, surentraînement

\begin{abstract}
Résumé
Nine elite male junior weightlifters (mean age $17.6 \pm 0.3$ yrs) performed weightlifting tests before (Test 1) and after (Test 2) 1 week of increased training volume (overreaching) and repeated the protocol after 1 year of their training program. Strength increased by Year 2 ( $\mathrm{p}<0.05)$ but did not change during either week of increased training volume. The 1-week overreaching stimulus resulted in attenuated exercise-induced testosterone concentrations during Year 1, but augmented exercise-induced testosterone concentrations during Year 2. Testosterone concentrations at 7 a.m. decreased for only Year 1. For both years, the 1-week overreaching stimulus increased cortisol at 7 a.m., indicative of the increased training volumes. Testosterone/cortisol was not affected by increased training volume for either year. One year of chronic weightlifting and prior exposure to the overreaching stimulus appears to decrease the detrimental effects of stressful training on the endocrine system.
\end{abstract}

Neuf haltérophiles d'élite juniors (17,6 $\pm 0,3$ ans) passent des tests de force avant (test 1) et après (test 2) une semaine d'entraînement dont le volume est augmenté (surentraînement); ces tests cont repris après une année d'entraînement. À la deuxième année, la force est plus grande $(\mathrm{p}<0,05)$ mais n' est pas modifiée à ni l'une ni l'autre des semaines

Fry: Coll. of Osteopathic Medicine, Ohio U., Athens, OH 45701; Kraemer and Gordon: Center for Sports Medicine, Penn State U., University Park, PA 16802; Stone and Warren: Dept. of HLES, Appalachian State U., Boone, NC 28608; Fleck and Kearney: Sports Science \& Technology, U.S. Olympic Committee, Colorado Springs, CO 80909. 
de surentraînement. La première semaine de surentraînement se traduit par une diminution de la concentration de testostérone à l' effort ( $I^{\text {re }}$ année); cette même concentration est à la hausse au cours de la deuxième semaine (2‘ année). La concentration de testostérone à 7 heures du matin diminue seulement au cours de la première année. La concentration de cortisol à la même heure augmente à la suite de chacune des deux semaines de surentraînement; cette augmentation traduit bien la présence d'un surentraînement. Le ratio de testostérone/cortisol ne varie pas d' une année à l'autre. Une année d' haltérophilie chronique et une première expérience de surentraînement semblent atténuer les effets nuisibles d'une entraînement intense sur le système endocrinien.

\section{Introduction}

Optimal training programs are a primary concern for those involved with athletic performance. In the pursuit of improved performance, it is critical to avoid Overtraining, which is defined as an increase in training volume and/or training intensity resulting in performance decrements (Barron et al., 1985; van Borselen et al., 1992). It is common practice in some sports to purposely increase training Volume or intensity for short periods as a way to alter the training stress. This phase of training has been termed overreaching (Stone et al., 1991; van Borselen et al., 1992) and does not result in long-term performance decrements. It is well known that chronic resistance exercise will result in adaptations of the endocrine system (Häkkinen et al., 1985; 1988). The endocrine system has therefore been suggested as a potential indicator of overtraining (Stone et al., 1991).

In male weightlifters, resting testosterone concentrations are increased following 2 years of training (Häkkinen et al., 1988b), but not necessarily after Only 1 year (Häkkinen et al., 1987). This indicates that the amount of exposure to training is important in altering the activity of the hypothalamic-pituitarygonadal axis. The changes in resting hormonal concentrations (i.e., testosterone, Cortisol, testosterone/cortisol) of male weightlifters appear to reflect the characteristics of the short-term and long-term training programs (Busso et al., 1992; Häkkinen and Pakarinen, 1991; Häkkinen et al., 1987). Dramatic increases in resting testosterone concentrations are observed in strength trained subjects as they progress from prepuberty to puberty with large concomitant strength increases (Mero et al., 1989), but pubertal weightlifters have not demonstrated further increases in resting testosterone concentrations over 1 year of training (Mero et al., 1985). Furthermore, 2 years of training experience with other forms of resistance exercise have not been associated with increased resting testosterone concentrations in adolescent males (Fahey et al., 1976).

Few investigators have monitored endocrine responses to resistance exercise using exercise-induced (acute) hormonal concentrations (Kraemer, 1988). Cross-sectional study of adolescent weightlifters has demonstrated increased exercise-induced serum testosterone concentrations after more than 2 years of training (Kraemer et al., 1992). It is important to note that acute hormonal responses to resistance exercise are not identical to chronic (resting) responses (A.C. Fry et al., 1992; 1993; Häkkinen et al., 1988a), and may be controlled by different regulatory mechanisms (R.W. Fry et al., 1991). Thus more can be known about the endocrine system when both resting and exercise-induced hormonal concentrations are monitored.

Variations in the design of the resistance exercise program, for example 
number of sets, number of repetitions, length of rest intervals, or muscle mass involved, can produce considerable differences in the exercise-induced endocrine responses (Kraemer et al., 1990). The site of action of the endocrine adaptations to chronic resistance exercise is not entirely clear. Functional changes in the hypothalamic-pituitary-testicular or hypothalamic-pituitary-adrenal axes can produce alterations in a number of trophic hormones, resulting in altered concentrations of testosterone or cortisol (Kraemer, 1988). Functional changes in peripheral endocrine tissue (e.g., testes), such as secretory or blood flow characteristics, may also contribute to a chronic resistance exercise response (Kraemer et al., 1991). The cybernetic regulatory mechanism of the endocrine system in males suggests hormonal mechanisms may be a site of considerable training adaptations.

Previous investigations have not studied long-term adaptations of acute endocrine concentrations in response to an overreaching stimulus. Therefore the purpose of the present investigation was to determine whether the exerciseinduced serum concentrations of testosterone, cortisol, and the testosterone/cortisol ratio in response to 1 week of dramatically increased training volumes are altered after 1 year of an elite weightlifting training program, and whether these responses differ from resting endocrine adaptations.

\section{Materials and Methods}

Nine male participants from 2 consecutive years of junior age-group U.S. national weightlifting training camps served as subjects for this investigation (mean $\pm S E$ for 1st year: age $17.6 \pm 0.3 \mathrm{yrs}$, height $167.9 \pm 2.1 \mathrm{~cm}$, body weight $63.9 \pm 3.6$ $\mathrm{kg}$ ). Each subject placed first or second both years in drug tested national competition according to his age group and weight class and was subsequently selected to participate in these training camps. All subjects had repeatedly tested negative for drug use. Prior to the study, each subject was informed of the experimental risks and signed an informed consent document with the approval of his parents/guardians. Complete descriptive data are listed in Table 1. Relative body fat levels were anthropometrically estimated (Jackson and Pollock, 1979; Siri, 1961), and one repetition maximum (RM) values for th.. wo competitive lifts (i.e., snatch, clean and jerk) were determined from their best previous competitive performances. The elite status of these individuals is indicated by their previous and subsequent athletic accomplishments: 5 subjects selected to the Junior World Team, 4 Pan-American Games medalists, 5 senior U.S. National champions, and 3 Olympic Team members.

The following test battery was administered between 2 and 5 p.m. before and after 1 week of each training camp for both years. Blood samples were obtained at 7 a.m. following a fast of $12 \mathrm{hrs}$. After an additional 6-hr fast, blood was drawn immediately preexercise and at 5 and 15 min postexercise to determine concentrations of total testosterone (Tes), cortisol (Cort), the ratio of Tes/Cort, and whole blood lactate (HLa). Blood samples were taken from an antecubital vein via venipuncture using a 20 -gauge needle and vacutainers containing either no preservatives (for Tes, Cort) or sodium heparin (for HLa).

The test procedures have previously been described in detail (Kraemer et al., 1992). Briefly, the test session consisted of a set of 15 vertical jumps (1 jump every $3 \mathrm{sec}$ ) followed by a 1 -min rest. After performing 10 reps at $40 \%$ of 1-RM, single repetitions of the snatch lift were then performed every $15 \mathrm{sec}$ with 
Table 1 Subject Characteristics and Test Session Results (mean $\pm S E, N=9$ )

\begin{tabular}{|c|c|c|c|c|c|c|c|c|}
\hline \multirow[b]{3}{*}{ Variable } & \multicolumn{4}{|c|}{ Year 1} & \multicolumn{4}{|c|}{ Year 2} \\
\hline & \multicolumn{2}{|c|}{ Test 1} & \multicolumn{2}{|c|}{ Test 2} & \multicolumn{2}{|c|}{ Test 1} & \multicolumn{2}{|c|}{ Test 2} \\
\hline & $M$ & $S E$ & $M$ & $S E$ & $M$ & $S E$ & $M$ & $S E$ \\
\hline Age (yrs) & 17.6 & 0.3 & & & 18.6 & 0.3 & & \\
\hline Height $(\mathrm{cm})$ & 167.9 & 2.1 & & & 168.1 & 2.4 & & \\
\hline Body weight (kg) & 63.9 & 3.6 & & & 65.7 & 3.9 & & \\
\hline Relative fat $(\%)$ & 5.0 & 0.3 & & & 4.7 & 0.5 & & \\
\hline Fat free mass $(\mathrm{kg})$ & 60.7 & 3.4 & & & 62.5 & 3.6 & & \\
\hline Years trained & 3.6 & 0.5 & & & 4.6 & 0.5 & & \\
\hline 1-RM snatch $(\mathrm{kg})$ & 91.9 & 7.3 & & & 98.9 & $6.7 *$ & & \\
\hline 1-RM clean \& jerk $(\mathrm{kg})$ & 116.7 & 8.3 & & & 127.8 & $7.7 *$ & & \\
\hline \multicolumn{9}{|l|}{ Test session- } \\
\hline Test snatch (kg) & 79.4 & 6.7 & 83.3 & 6.2 & 88.3 & $5.1^{*}$ & 90.0 & $6.1^{*}$ \\
\hline Successful lifts & 7.6 & 0.8 & 8.3 & 0.6 & 8.7 & 0.5 & 9.4 & 0.6 \\
\hline$\%$ 1-RM attained & 86.1 & 2.9 & 90.5 & 1.9 & 89.9 & 2.0 & 91.2 & 2.0 \\
\hline $\begin{array}{l}\text { Lactate, } 5 \text { min post } \\
\quad\left(\mathrm{mmol} \cdot \mathrm{L}^{-1}\right)\end{array}$ & 10.7 & 0.6 & 6.7 & $0.5^{* *}$ & 7.9 & $0.8^{*}$ & 5.6 & $0.4 * *$ \\
\hline
\end{tabular}

*Different from Year $1, p<0.05 ; * *$ different from Test $1, p<0.05$.

the resistance increased by $5 \mathrm{~kg}$ after each successful lift. The initial resistance for all subjects was $50 \%$ of 1-RM based on their best competitive performances. These were performed until two successive attempts were unsuccessful. After a 3 -min rest interval the protocol concluded with three sets of 10 repetitions, with 1 -min rest intervals, of the snatch pull exercise performed at $65 \%$ of $1-\mathrm{RM}$ for the snatch and at a cadence of one every $4 \mathrm{sec}$. Figure 1 illustrates the test protocol and Table 1 lists the results of each test session.

The test battery was performed before (Test 1) and after (Test 2) 7 days of training, during which training volume was at least doubled for all subjects ( 2 to 4 training sessions a day). Training programs for all subjects prior to each year of the study were of similar volume and intensity and consisted of 3 to 6 sessions a week, with no subjects training more than once a day. Typical training sessions included exercises such as snatches, cleans, jerks, snatch pulls, clean pulls, front squats, and back squats. Training loads ranged from 70 to $100 \%$ of 1 RM for each exercise. The training and test protocols for each year were identical.

Whole blood HLa concentrations were immediately determined in duplicate via enzymatic techniques using a YSI 23L lactate analyzer (Yellow Springs, Inc., Yellow Springs, $\mathrm{OH}$ ). Whole blood for Tes and Cort determinations was allowed

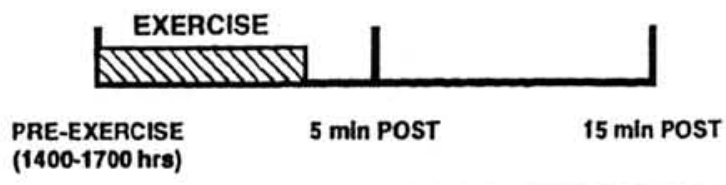

Figure 1. Testing protocol. 
to clot at room temperature and was then centrifuged at $1,500 \times \mathrm{g}$ for $15 \mathrm{~min}$. Aliquots of the resulting serum were stored at $-90^{\circ} \mathrm{C}$ and thawed only once before analysis. Radioimmunoassays $\left({ }^{125} \mathrm{I}\right)$ were performed in duplicate for each hormone. Sample identification was decoded only after analyses were completed (i.e., blinded analysis procedure). Serum Tes and Cort were both analyzed using solid phase radioimmunoassay techniques (Diagnostic Systems, Webster, TX, and ICN Biomedicals, Carson, CA). Intra-assay variances for both hormones were $<3.0 \%$, and inter-assay variances were $<6.8 \%$. Immunoreactivity values and corresponding hormone concentrations were determined with an LKB-Wallac 1272 Clinigamma automatic gamma counter (Pharmacia LKB Nuclear, Turku, Finland) with an online data reduction system. Exercise-induced plasma volume shifts (change from pre to 5 min postexercise) of $<10 \%$ were estimated by the methods of Dill and Costill (1974).

Comparisons between Year 1 and Year 2 subject characteristics were analyzed with dependent $t$ tests. Blood variables were analyzed with $2 \times 2 \times 3$ (Year $\times$ Test $\times$ Time) repeated measures analyses of variance. Fisher's protected LSD procedures and dependent $t$ tests were used for post hoc analyses. Significance was at $p<0.05$ throughout the investigation.

\section{Results}

Physical characteristics (see Table 1) were similar for both years. All subjects had already been exposed to more than 2 years of weightlifting training when this study began. Competitive lifting performances and test lifts increased from Year 1 to Year 2, although test lifts did not change during the week of increased volume training for either year. Other test battery performances (i.e., number of attempted lifts, \% 1-RM attained for snatch lift) were similar for all tests. Exercise-induced HLa responses decreased from Year 1 to Year 2 only for Test 1. Furthermore, both years demonstrated a decreased HLa response by Test 2 when compared to Test 1.

Figure 2 illustrates the Tes, Cort, and Tes/Cort responses. Exercise-induced increases in Tes were generally observed; they were not entirely due to the plasma volume shifts since the relative hormonal increases $(\%)$ were considerably greater than the relative plasma volume shifts (\%). Relative plasma volume shifts were similar for all test batteries of both years. Exercise-induced Tes responses for Test 1 were also similar for both years. For all time points of Test 2, Year 2 exhibited greater Tes concentrations than Year 1. This difference was a product of the general decreases in Tes from Test 1 to Test 2 in Year 1, and to the general increase in Tes from Test 1 to Test 2 in Year 2. Overall, 1 week of increased volume training during Year 1 resulted in decreased Tes concentrations at $5 \mathrm{~min}$ postexercise $\left(-5.9 \mathrm{nmol} \cdot \mathrm{L}^{-1}[-25.4 \%]\right)$ and $15 \mathrm{~min}$ postexercise $(-6.3 \mathrm{nmol}$. $\left.\mathrm{L}^{-1}[-29.2 \%]\right)$. On the other hand, 1 week of increased volume training during Year 2 produced increased Tes concentrations at 5 min postexercise $(+6.0 \mathrm{nmol}$ $\left.\cdot \mathrm{L}^{-1}[+31.4 \%]\right)$ and $15 \mathrm{~min}$ postexercise $\left(+6.5 \mathrm{nmol} \cdot \mathrm{L}^{-1}[+35.5 \%]\right)$. Tes concentrations at 7 a.m. were greater for Year 2 than for Year 1. During Year 1, Tes at 7 a.m. decreased by Test 2 while no changes were observed during Year 2.

All tests produced marked exercise-induced increases in Cort concentrations. Exercise-induced Cort responses were similar each year, with both years demonstrating decreased exercise-induced responses by Test 2 . The relative increases for exercise-induced Cort concentrations (\%) were greater than the relative 


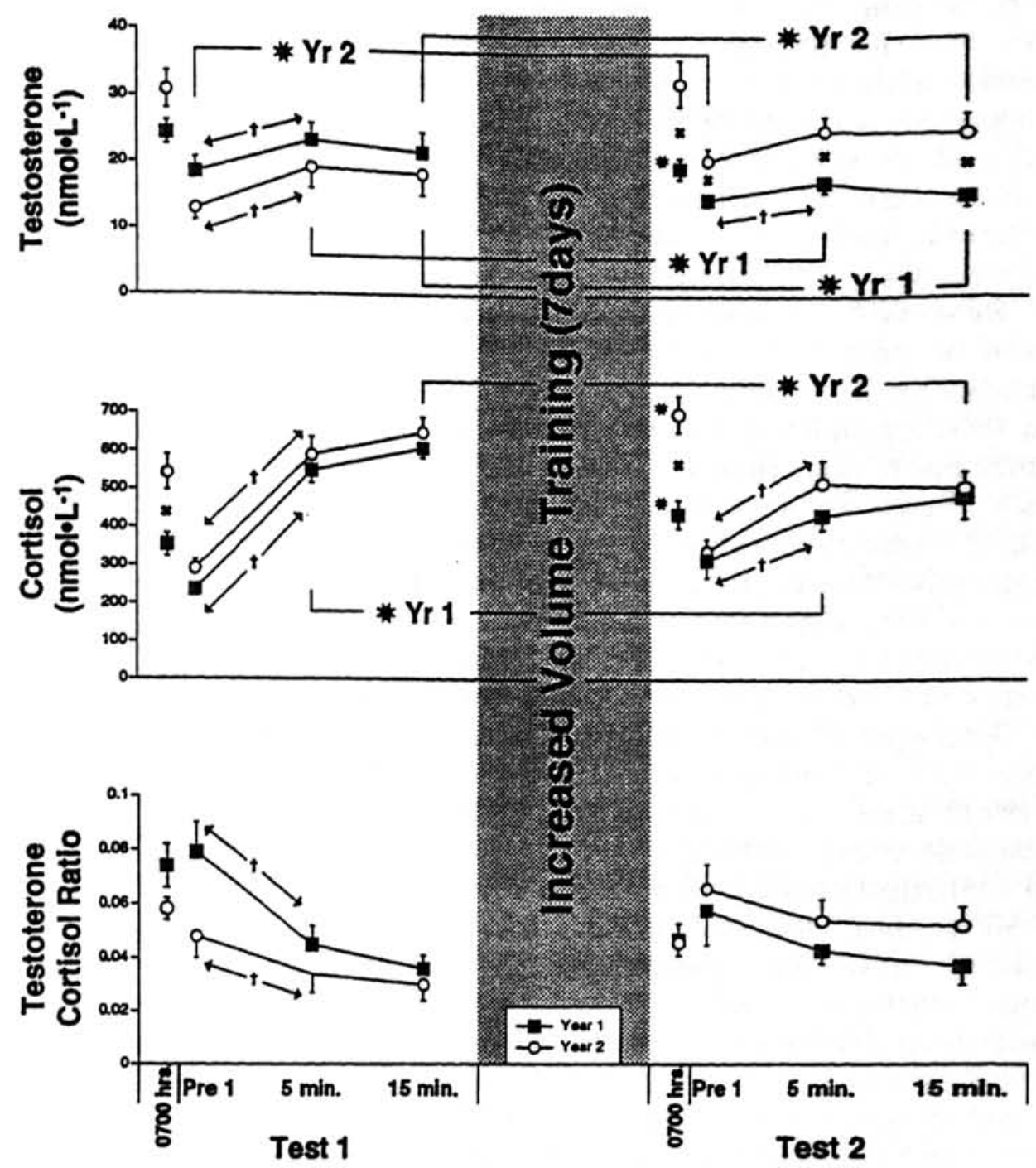

Figure 2. Testosterone and cortisol concentrations, and testosterone/cortisol values (mean $\pm S E, p<0.05)$. + different from preexercise, $\times$ different from Year 1 , *different from Test. 1.

plasma volume shifts (\%) for all test sessions. Cort at 7 a.m. increased by Test 2 during both years. Test 1 demonstrated decreased exercise-induced Tes/Cort for both years, although this acute decrease was not evident by Test $\mathbf{2}$ for either year. Otherwise no differences were observed between tests or years. By Test 2 for both years, Tes/Cort did not demonstrate any significant differences across time (from preexercise to $15 \mathrm{~min}$ post). Test/Cort at 7 a.m. was unaffected by the 1 week of increased volume training.

\section{Discussion}

The primary finding of this study is that exercise-induced Tes concentrations in response to 1 week of an overreaching stimulus (i.e., increased volume weightlifting training, no performance decrements) are augmented after 1 year of contin- 
ued training and prior exposure to the overreaching stimulus. This is particularly evident by the different Tes responses for Test 2 of each year. Although the increased training volumes of Year 1 resulted in decreased Tes concentrations, the opposite was true for Year 2, with exercise-induced Tes concentrations at both 5 and 15 min postexercise increased by $>30 \%$ from Test 1 to Test 2 . Previous studies of male weightlifters have exhibited decreased resting Tes concentrations in response to increased volumes of training (Häkkinen et al., 1988a), which were also reported for only Year 1 for the subjects in the present study.

Resting Tes was unchanged during Year 2. This indicates that the adaptations of resting ( 7 a.m.) and exercise-induced Tes responses to overreaching are not identical. Overtraining had not occurred in the present study, since the subjects were able to maintain strength performances during the week of high volume training each year. However, a state of overreaching was attained, as indicated by attenuated vertical jump performances (Warren et al., 1992) as previously reported, and by impaired kinematic characteristics during the snatch lift as determined from digitized video analysis (unpublished observations). Weightlifting training experience of more than 2 years has previously been associated with increased exercise-induced Tes responses (Kraemer et al., 1992), perhaps indicative of a chronic response similar to what was observed in the current study.

The role of anabolic hormones such as Tes and potentially catabolic hormones such as Cort in resistance exercise may be considerable (Deschenes et al., 1991; Kraemer, 1988). Changes in resting concentrations of Tes, Cort, and the ratio of these two hormones reflect changes in both the long-term and shortterm training stresses (Adlercreutz et al., 1986; Alén et al., 1988; Häkkinen et al., 1985; 1987; Häkkinen and Pakarinen, 1991; Urhausen et al., 1987). Morning hormonal ratios (i.e., Tes/Cort, free Tes/Cort) have been related to long-term strength increases (Alén et al., 1988) and have been suggested as markers of overtraining (Adlercreutz et al., 1986; Vervoorn et al., 1991). Previous studies of weightlifting, however, have failed to observe a positive relationship between absolute Tes concentrations and muscular strength (Kraemer et al., 1992; Mero et al., 1985). The role of elevated acute Tes responses in the expression of muscular strength may be considerable since it will result in greater exposure of androgen receptors to their ligands. In addition, Tes interacts with other physiological systems such as the nervous system as well as with the growth hormone mediated regulation of insulin-like growth factors (Kraemer, 1992a).

There is the question as to what physiological mechanisms were responsible for the Tes responses observed. More than other hormones, testosterone appears to chronically respond to weightlifting (Häkkinen et al., 1988b; Kraemer et al., 1992), as was observed in the present study. Dietary intakes were normal for these subjects, as previously reported (A.C. Fry et al., 1992; 1993). Strength performances did increase despite the lack of increased fat free mass, suggesting that muscle hypertrophy was not the primary mechanism for the increased strength. Although anabolic hormone activity appears to contribute to the performances of male weightlifters (Häkkinen et al., 1987; 1988b), neural factors can also influence strength gains with weightlifting (Häkkinen et al., 1988b) and other types of resistance exercise (Rutherford and Jones, 1986). These neural alterations can be quite dramatic (Sale, 1992) and seem to occur before skeletal muscle hypertrophy is evident (Moritani, 1992). This appears to have been the case with the highly accomplished subjects in the present study. The augmented Tes concentrations observed for Test 
2 of Year 2 (i.e., 7 a.m. preexercise, 15 min postexercise) were not associated with increases in lean body mass. If the increased strength exhibited at Year 2 was influenced in part by circulating Tes concentrations, a mechanism other than skeletal muscle hypertrophy appears to have been responsible.

Another line of thought involves the attenuated HLa response for Year 2. This may indicate a higher level of fitness going into the 2nd year of testing, perhaps contributing to a decreased stress of training. In this manner the stress of training may have been less for Year 2, thus avoiding decreases in Tes concentrations as previously reported with stressful strength training (A.C. Fry et al., 1992; 1993; Häkkinen et al., 1988a). Maturation levels of the subjects in the present study most likely did not account for the altered exercise-induced endocrine responses observed. Mero et al. (1985) found that 1 year of chronic weightlifting training did not alter resting Tes concentrations in pubertal subjects, and Kraemer et al. (1992) found that adolescents needed 2 years of prior weightlifting experience before exercise-induced responses were affected. Evidence of the subjects' developing maturity is apparent by the increasing Tes at 7 a.m. from Year 1 to Year 2. Since no significant differences were observed between Years 1 and 2 for the pre- or postexercise Tes concentrations at Test 1 , maturation does not appear to be responsible for the Tes responses observed at Test 2 during Year 2.

Exercise-induced endocrine responses are most likely influenced by different regulatory control mechanisms than are resting concentrations (R.W. Fry et al., 1991). As a result, valuable information may be obtained when an exercise stimulus is incorporated into the study design. Although resting hormonal concentrations have been used to monitor weight training subjects, the data presented here suggest that exercise-induced concentrations are also sensitive to the physiological changes occurring over 1 year. Significant Tes concentration increases have been observed postresistance exercise (Deschenes et al., 1991; Kraemer et al., 1990; 1992), as was observed each year in the present study. These increases are dependent on exercise intensity (Jezová et al., 1985), amount of involved muscle mass, rest intervals, and relative loads (Kraemer et al., 1990). The presence of plasma volume shifts of $<10 \%$ would certainly have contributed to the increased Tes concentrations but did not account for the entire acute Tes concentration increase, which was always $\geq 20 \%$. Although Tes concentrations have been adjusted for plasma volume shifts in prior resistance exercise investigations (Schwab et al., 1993), unadjusted Tes values are reported in the present study to more accurately reflect the actual circulating hormonal concentrations to which the androgen receptors are exposed. In addition, correcting for plasma volume shifts did not alter the hormonal patterns observed. Since numerous mechanisms can contribute to exercise-induced hormonal concentrations (Kraemer, 1992b), future studies of postresistance exercise hormonal kinetics are warranted.

The role of bound versus free Tes in the circulation and its effect on bioavailability must also be addressed in future investigations of this training stimulus. It should be noted, however, that chronic weightlifting training of 2 years has produced no changes in sex hormone binding globulin whereas total testosterone was augmented (Häkkinen, 1988b). In addition, the exercise-induced free Tes/total Tes ratio has not been observed to change when performing heavy, total body resistance exercise to failure, despite the presence of mean plasma volume shifts of $-15.9 \%$ (A.C. Fry et al., unpublished observations). Therefore, monitoring total Tes concentrations, unadjusted for plasma volume shifts, pro- 
vides useful information on the endocrine environment resulting from acute and chronic weightlifting exercise.

It is not likely that the augmented Tes concentration (i.e., preexercise, 15 min postexercise) observed at Test 2 of Year 2 are due to hypothalamic-pituitary regulation via leutinizing hormone (Häkkinen et al., 1988a), although alteration of this regulatory axis has been demonstrated with aerobic overtraining (Barron et al., 1985). Increases in exercise-induced Tes may also be due to sympathetic nervous system activity (Eik-nes, 1969; Jezová and Vigas, 1981; Jezová et al., 1985). Stressful training has been shown to influence sympathetic nervous system activity (Lehmann et al., 1992), thus possibly affecting catecholamine regulation of acute Tes concentrations. It is possible that either sympathetic nervous system exhaustion or down regulation of testicular adrenergic receptors occurred during Year 1 but not Year 2. Such adaptations could contribute to the augmented Tes responses for Year 2. It is not likely that altered Tes clearance is responsible for the acute responses observed in the present study (Kraemer et al., 1991). There is a need for additional study to investigate the potential role of sympathetic nervous system regulation of testicular activity with chronic resistance exercise.

Elevated Cort at 7 a.m. by Test 2 for both years is indicative of the increased stress of the 1-week training program (Häkkinen and Pakarinen, 1991), providing evidence of the overreaching state the subjects achieved. Exercise-induced Cort concentration increases were observed for each test, as has been reported on previous resistance exercise investigations (Häkkinen et al., 1985; Kraemer et al., 1992). The acute responses were slightly decreased by Test 2 of both years, suggesting diminished activity of the hypothalamic-pituitary-adrenal cortex axis following increased weightlifting training volumes. Overall, few differences were observed in pre- and postexercise Cort concentrations between Years 1 and 2, suggesting that 1 year of weightlifting training and prior exposure to the overreaching stimulus did not change acute Cort regulation.

The ratio of Tes/Cort demonstrated exercise-induced decreases for Test 1 of both years, similar to previous weightlifting studies (A.C. Fry et al., 1993; Kraemer et al., 1992). Contrary to previous data on increased volume training (Adlercreutz et al., 1986; Alén et al., 1988; Häkkinen et al., 1987), Tes/Cort did not decrease at any given time by Test 2 for either Year 1 or Year 2. The subjects exhibited less variability in this ratio after the week of stressful training. Furthermore, this response was not affected by 1 year of training. The stability of this variable is evidence that there was no overtraining phenomenon (Adlercreutz et al., 1986). The protocol used in the present investigation appears to be simply an overreaching phase of training involving increased training volumes. The Tes/Cort measure does not appear to be very sensitive to this particular short-term (i.e., 1 week) training stress.

In summary, 1 year of continuous weightlifting training and prior exposure to an overreaching stimulus resulted in augmented exercise-induced Tes concentrations after 1 week of increased training volumes. As has been reported for the sport of weightlifting, this positive training adaptation was observed primarily for Tes, while Cort and Tes/Cort demonstrated few changes. Since resting and acute endocrine responses to the overreaching protocol are under different regulatory control, hormonal responses to an exercise stimulus are necessary to adequately monitor acute endocrine adaptations. From a practical standpoint, use of this type of overreaching stimulus may be beneficial early in an athlete's career 
to allow development of a physiological toleration of this type of training. Further study is required to determine alterations in the acute regulatory mechanisms of the testes with this type of training protocol.

\section{References}

Adlercreutz, H., Härkönen, M., Kuoppasalmi, K., Näveri, M., Huhtaniemi, I., Tikkanen, H., Remes, K., Dessypris, A., and Karvonen, J. (1986). Effect of training on plasma anabolic and catabolic steroid hormones and their response during physical exercise. Int. J. Sports Med. 7 (Suppl.): 27-28.

Alén, M., Pakarinen, A., Häkkinen, K., and Komi, P.V. (1988). Responses of serum adrogenic-anabolic and catabolic hormones to prolonged strength training. Int. J. Sports Med. 9: 229-233.

Barron, J.L., Noakes, T.D., Levy, W., Smith, C., and Millar, R.P. (1985). Hypothalamic dysfunction in overtrained athletes. J. Clin. Endocrinol. Metab. 60: 803-806.

Busso, T., Häkkinen, K., Pakarinen, A., Kauhanen, H., Komi, P.V., and Lacour, J.R. (1992). Hormonal adaptations and modified responses in elite weightlifters during 6 weeks of training. Eur. J. Appl. Physiol. 64: 381-386.

Deschenes, M.R., Kraemer, W.J., Maresh, C.M., and Crivello, J.F. (1991). Exercise induced hormonal changes and their effects upon skeletal muscle tissue. Sports Med. 12: 80-93.

Dill, D.B., and Costill, D.L. (1974). Calculation of percentage changes in volume of blood, plasma and red cells in dehydration. J. Appl. Physiol. 37: 247-248.

Eik-nes, K.B. (1969). An effect of isoproterenol on rates of synthesis and secretion of testosterone. Am. J. Physiol. 217: 1764-1770.

Fahey, T.D., Rolph, R., Moungmee, P., Nagel, J., and Mortara, S. (1976). Serum testosterone, body composition, and strength of young adults. Med. Sci. Sports 8: 31-34.

Fry, A.C., Kraemer, W.J., Stone, M.H., Kearney, J.T., Fleck, S.J., Thrush, J., Gordon, S.E., and Triplett, N.T. (1992). Endocrine and performance responses during one month of periodized weightlifting with amino acid supplementation [abstract]. J. Appl. Sport Sci. Res. 6: 183.

Fry, A.C., Kraemer, W.J., Stone, M.H., Warren, B., Kearney, J.T., Fleck, S.J., and Weseman, C.A. (1993). Endocrine and performance responses to high volume training and amino acid supplementation in elite junior weightlifters. Int. J. Sports Nutr. 3: 306-322.

Fry, R.W., Morton, A.R., and Keast, D. (1991). Overtraining in athletes: An update. Sports Med. 12: 32-65.

Häkkinen, K., and Pakarinen, A. (1991). Serum hormones in male strength athletes during intensive short term strength training. Eur. J. Appl. Physiol. 63: 194-199.

Häkkinen, K., Pakarinen, A., Alén, M., Kauhanen, H., and Komi, P.V. (1987). Relationships between training volume, physical performance capacity, and serum hormone content ratios during prolonged training in elite weight lifters. Int. J. Sports Med. 1 (Suppl.): 61-65.

Häkkinen, K., Pakarinen, A., Alén, M., Kauhanen, H., and Komi, P.V. (1988a). Daily hormonal and neuromuscular responses to intensive strength training in 1 week. Int. J. Sports Med. 9: 422-428.

Häkkinen, K., Pakarinen, A., Alén, M., Kauhanen, H., and Komi, P.V. (1988b). Neuromuscular and hormonal adaptations in athletes to strength training in two years. J. Appl. Physiol. 65: 2406-2412.

Häkkinen, K., Pakarinen, A., Alén, M., and Komi, P.V. (1985). Serum hormones during prolonged training of neuromuscular performance. Eur. J. Appl. Physiol. 53: 287-293.

Jackson, A.S., and Pollock, M.L. (1979). Generalized equations for predicting body density of men. Br. J. Nutr. 70: 497-504.

Jezová, D., and Vigas, M. (1981). Testosterone response to exercise during blockade and stimulation of adrenergic receptors in man. Horm. Res. 15: 141-147. 
Jezová, D., Vigas, M., Tatár, P., Kvetnansky, R., Nazar, K., Kaciuba-Uscilko, H., and Kozlowski, S. (1985). Plasma testosterone and catecholamine responses to physical exercise of different intensities in men. Eur. J. Appl. Physiol. 54: 62-66.

Kraemer, W.J. (1988). Endocrine responses to resistance exercise. Med. Sci. Sports Exerc. 20 (Suppl.): S152-S157.

Kraemer, W.J. (1992a). Hormonal mechanisms related to the expression of muscular strength and power. In: P.V. Komi (Ed.), Strength and Power in Sport, pp. 6476. London: Blackwell Scientific.

Kraemer, W.J. (1992b). Endocrine responses and adaptations to strength training. In: P.V. Komi (Ed.), Strength and Power in Sport, pp. 291-304. London: Blackwell.

Kraemer, W.J., Fry, A.C., Warren, B.J., Stone, M.H., Fleck, S.J., Kearney, J.T., Conroy, B.P., Maresh, C.M., Weseman, C.A., Triplett, N.T., and Gordon, S.E. (1992). Acute hormonal responses in elite junior weightlifters. Int. J. Sports Med. 13: 103-109.

Kraemer, W.J., Gordon, S.E., Fleck, S.J., Marchitelli, L.J., Mello, R., Dziados, J.E., Friedl, K., Harman, E., Maresh, C., and Fry, A.C. (1991). Endogenous anabolic hormonal and growth factor responses to heavy resistance exercise in males and females. Int. J. Sports Med. 12: 228-235.

Kraemer, W.J., Marchitelli, L., Gordon, S.E., Harman, E.A., Dziados, J.E., Mello, R., Frykman, P.N., McCurry, D., and Fleck, S.J. (1990). Hormonal and growth factor responses to heavy resistance exercise protocols. J. Appl. Physiol. 69: 1742-1750.

Lehmann, M., Schnee, W., Sheu, R., Stockhausen, W., and Bachl, N. (1992). Decreased nocturnal catecholamine excretion: Parameter from overtraining syndrome in athletes: Int. J. Sports Med. 13: 236-242.

Mero, A., Häkkinen, K., and Kauhanen, H. (1985). Hormonal profile and strength development in young weight lifters. J. Hum. Mvmt. Stud. 16: 255-266.

Mero, A., Kauhanen, H., Peltola, E., and Vuorimaa, T. (1989). Transfer from prepuberty to puberty: Effects of three years of training. J. Hum. Mvmt. Stud. 16: 267-278.

Moritani, T. (1992). Time course of adaptations during strength and power training. In: P.V. Komi (Ed.), Strength and Power in Sport, pp. 266-278. London: Blackwell.

Rutherford, O.M., and Jones, D.A. (1986). The role of learning and coordination in strength training. Eur. J. Appl. Physiol. 55: 100-105.

Sale, D.G. (1992). Neural adaptation to strength training. In: P.V. Komi (Ed.), Strength and Power in Sport, pp. 249-265. London: Blackwell Scientific.

Schwab, R., Johnson, G.O., Housh, T.J., Kinder, J.E., and Weir, J.P. (1993). Acute effects of different intensities of weight lifting on serum testosterone. Med. Sci. Sport Exerc. 25: 1381-1385.

Siri, W.E. (1961). Body composition from fluid spaces and density: Analysis of methods. In: Techniques for Measuring Body Composition, pp. 223-244. Washington, DC: National Academy of Sciences.

Stone, M.H., Keith, R.E., Kearney, J.T., Fleck, S.J., Wilson, G.D., and Triplett, N.T. (1991). Overtraining: A review of the signs, symptoms and possible causes. J. Appl. Sport Sci. Res. 5: 35-50.

Urhausen, A., Kullmer, T., and Kindermann, W. (1987). A 7-week follow-up study of the behaviour of testosterone and cortisol during the competition period in rowers. Eur. J. Appl. Physiol. 56: 528-533.

van Borselen, F., Vos, N.H., Fry, A.C., and Kraemer, W.J. (1992). The role of anaerobic exercise in overtraining. Natl. Strength Cond. Assoc. J. 14(3): 74-79.

Vervoorn, C., Quist, A.M., Vermulst, L.J.M., Erich, W.B.M., deVries, W.R., and Thijssen, J.H.H. (1991). The behaviour of plasma free testosterone/cortisol ratio during a season of elite rowing training. Int. J. Sports Med. 12: 257-263.

Warren, B.J., Stone, M.H., Kearney, J.T., Fleck, S.J., Wilson, G.D., and Kraemer, W.J. (1992). The effects of short-term overwork on performance measures and blood metabolites in elite junior weightlifters. Int. J. Sports Med. 13: 372-376.

Received September 1, 1993; accepted in final form April 8, 1994. 